\title{
Production of Bio-Oil from Agriculture Waste
}

\section{Olfat AbdAllah Mohamed*}

Department of Chemical Engineering, Tanta University, Tanta, Egypt

\begin{abstract}
Biomass energy which includes producing energy fuel from plant is considered a promising source of renewable energy. This research aims to develop a new method to liquefy two types of agriculture waste and compare between their produced bio-oils in terms of ultimate production conditions, compositions and applications.

Firstly, One gram of two different types of agriculture wastes include Corn sticks (CS) and Palm leaves (PL) were liquefied by autoclaving at $2.5 \mathrm{~atm}$ pressure and $220^{\circ} \mathrm{C}$ temperature. The liquefaction process had been performed in the range of 10 to $80 \mathrm{ml}$ ethanol/g treated solid, and retention time ranges between 10 to 120 min., the produced bio-oil were extracted and separated into three fractions: volatile, light and heavy.

The results show that, the maximum amount $(0.04 \mathrm{~g} / \mathrm{g})$ of volatile bio-oil can be produced from CS at $40 \mathrm{ml}$ ethanol/g treated solid and $30 \mathrm{~min}$ retention time. However maximum amount of light bio-oil $(\mathrm{g} / \mathrm{g})$ was obtained from CS at $30 \mathrm{ml}$ ethanol/1 $\mathrm{g}$ treated solid and $60 \mathrm{~min}$ retention time. For heavy bio-oil, maximum amount $(0.25 \mathrm{~g} / \mathrm{g})$ was derived from CS when the ratio between ethanol $(\mathrm{ml})$ : treated solid $(\mathrm{g})$ is $30: 1$ and the retention time is $60 \mathrm{~min}$.

Experimental data had been analysed using matlab software to get the modules which give the relations between bio-oil produced, ethanol to solid ratio and retention time in order to get the ultimate conditions of the process. GC-MS and FTIR analysis has been done to identify the bio-oils compositions. The results show that produced bio-oil from CS is highly contained carbon atom from $\mathrm{C} 20-\mathrm{C} 38$ in addition it contains high percentage of $\mathrm{C} 6-\mathrm{C} 9$ atoms. Therefore, the bio-oil from CS can be used as bio-fuel. However, the produced bio-oil from PL is mainly unsaturated acids which has carbon atom from $\mathrm{C} 10-\mathrm{C} 18$. Thus, it has pharmaceutical applications.
\end{abstract}

Keywords: Bio-oil; Agriculture waste; Bio-fuel

\section{Introduction}

The current energy resources have limited reserves and are decreasing with increasing world opulation and fasting in developing technology [1]. The biomass resources are abundant all over the world [2]. The local utilization of biomass especially the residual biomass from agriculture is very low and the unused residual had been get rid of by unfriendly environmental way by burning these residual in field and produced black cloud saturated with carbon dioxide [3,4]. Renewal and abundance advantages of biomass make them attractive source for renewable energy. Biomass energy "bioenergy" which are producing biofuel and energy using plant is considered a promising technique as it has a recycled array [2].

Corn consider essential foods in many parts of the world, the annual global production is 864.96 million metricton, respectively. These cultivations produce yearly residues (leaves, stalk, straw) a proximately 1730 million metric ton [5]. The total amount of date palm trees all over the world is around 100 million [6]. In Egypt the total amount of agriculture residues from Corn reaches about 7.3 million ton of dry matter per year [5], and it has 16 million trees of date palm approximately. Every date palm under normal growth conditions formed an average 12-15 new leaves consequently the same amount can be expected to be cut as part of the maintenance of the palm [6]. Expected calculated amount of palm leaves (take weight of one dry leaf approximately 5 g) nearly 2.88 million $\mathrm{kg}$ of dry leaves many researches were done to produced bio-fuels from biomass by thermochemical conversion which offers a high range of technologies, the main principle can be used are: i) Direct liquefaction which refers to conversion of biomass to biofuel by means of using solvent with or without catalyst in one step without gasification's and synthesis intermediate steps using. This would be the most efficient way to produced fuel. ii) Indirect liquefaction which used synthesis gas generated from biomass gasification to produced high quality synthetic fuel [7]. Using of fast pyrolysis to produced bio-oil depend only on wood biomass no other agriculture waste [8-10]. Many solvent were used during liquefaction process such as water, ethanol, methanol and acetone. Although water is environmental friendly but Lie et al. [11] found that the bio-oil produced from biomass in water solvent have lower carbon content with low heating value. The role of solvent in liquefaction process is considering hydrogen donor in the reaction which induced a strong medium for destroying biomass molecular structure in addition increasing the yield of the liquid [11]. Biomass liquefaction is thermal-chemical reactions where macromolecular substances are decomposed into small molecules under heating conditions and in the presence of catalyst. During this process, lots of reactions occurred such as cracking, hydrogenation, hydrolysis and dehydration [12,13]. This can't define by single reaction step as the combination of cellulose, hemicellulose and lignin which interacts with each other leading to very complex chemistry [14].

Bio-oil is a kind of liquid fuel made from biomass materials such as agricultural crops, algal biomass, municipal wastes, agricultural and forestry by-products via thermo-chemical processes $[15,16]$. As one kind of new inexpensive, clean and green bio-energies, bio-oil is considered as an attractive option instead of conventional fuel in the aspect of reducing environmental pollution [17-19]. Bio-oil produced from rice straw contains high present of light constituents (C16-C19)

*Corresponding author: Olfat AbdAllah Mohamed, Department of Chemical Engineering, Tanta University, Tanta, Egypt, Tel: 01001289499; E-mail: omohamed2008@gmail.com

Received: August 04, 2017; Accepted: January 17, 2018; Published January 26, 2018

Citation: Mohamed OA (2018) Production of Bio-Oil from Agriculture Waste. Biochem Anal Biochem 7: 348. doi: 10.4172/2161-1009.1000348

Copyright: @ 2018 Mohamed OA. This is an open-access article distributed under the terms of the Creative Commons Attribution License, which permits unrestricted use, distribution, and reproduction in any medium, provided the original author and source are credited. 
and small parent of volatile bio-oil and heavy bio-oil [20]. The maximum amount of volatile, light and heavy bio oil produced at $30 \mathrm{ml}$ ethanol/g rice straw and retention time equal $60 \mathrm{~min}[20]$. The bio-oil obtained from rice straw constituents mainly from esters groups which can use as bio-fuel [20].

\section{Experimental Section}

\section{Materials preparations}

Rice straw, corn sticks, palm leaves, the samples were milled then dried at $105^{\circ} \mathrm{C}$ for $24 \mathrm{~h}$. the dried biomass powder was first extracted with chloroform/ethanol $(2 / 1 \mathrm{v} / \mathrm{v})$ for $6 \mathrm{~h}$, and the meal was allowed to dry in an oven at $80^{\circ} \mathrm{C}$ for $24 \mathrm{~h}$, then treated by $\mathrm{NaOH} 7.5 \%$ for $2 \mathrm{~h}$ and $17.5 \%$ for $2 \mathrm{~h}$ after that washed with distilled water until $\mathrm{pH}$ of washed water up to 7 then dried at $80^{\circ} \mathrm{C}$ for $24 \mathrm{~h}$ to remove the extractable materials [20-22].

\section{Liquefaction method}

The liquefaction experiments were carried out using autoclave at a working pressure $2.5 \mathrm{~atm}$ and working temperature $220^{\circ} \mathrm{C}$, the different solid to ethanol ratio studied at constant time by using $5 \mathrm{~g}$ of treated each solid and added to each one 100, 200,300, $400 \mathrm{ml}$ ethanol, the volatile. light and heavy types of produced oil extracted by water then by Acetone and distilled these are done at $15 \mathrm{~min}$, then all repeated at $30 \mathrm{~min}, 60 \mathrm{~min}$ and $90 \mathrm{~min}$. to Studied the effect of time on liquefaction process.

\section{Experimental analysis}

The Bio-oil produced were separated from the solvents by vacuum distillation then collected to analysis by using mass spectrophotometer gas chromatography model perkin elemer At acquisition parameters. Oven: Initial temp $45^{\circ} \mathrm{C}$ for $1.50 \mathrm{~min}$, ramp $15^{\circ} \mathrm{C} / \mathrm{min}$ to $300^{\circ} \mathrm{C}$, hold $11.50 \mathrm{~min}, \mathrm{Inj}=250^{\circ} \mathrm{C}$, Volume $=0 \mathrm{~L}, \mathrm{Split}=20: 1$, Carrier Gas $=\mathrm{He}$, Solvent Delay $=3.00 \mathrm{~min}$, Transfer Temp $=280^{\circ} \mathrm{C}$, Source Temp $=300^{\circ} \mathrm{C}$, Scan: 43 to $500 \mathrm{Da}$, Column $30.0 \mathrm{~m} \times 250 \mathrm{~m}[15,20,23]$. Either analysis by Fourier transformer infrared (FTIR) spectrophotometer with MCT detector and spectra region from $600-4000 \mathrm{~cm}^{-1}[20,24,25]$.

\section{Result and Discussion}

\section{Studying the effect of ethanol biomass ratio}

The conditions used in these experiments were selected to examine the effect of ethanol biomass ratio $10,20,30,40,60(\mathrm{ml}$ ethanol $/ \mathrm{g}$ biomass) on the bio oil production (Volatile bio-oil, Light bio-oil,

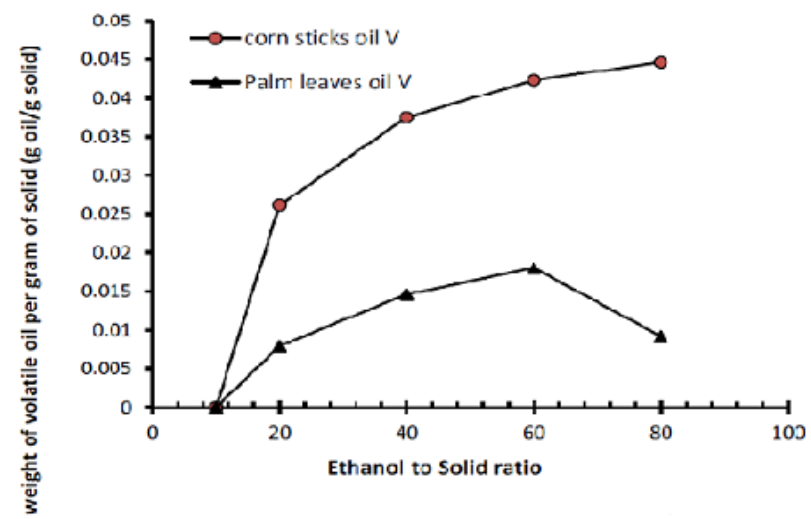

Figure 1: Relation between ethanol solid ratio and amount of volatile oil produce per gram solid at $30 \mathrm{~min}$ retention time.

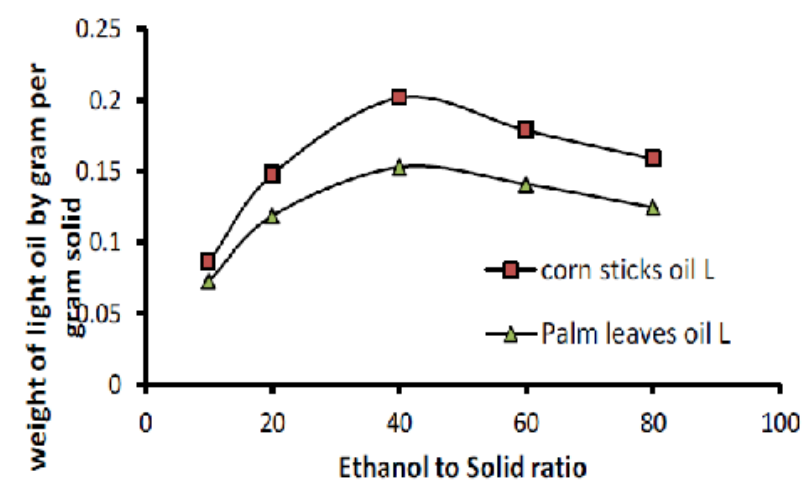

Figure 2: Relation between ethanol solid ratio and amount of light oil produce per gram solid at $30 \mathrm{~min}$ retention time.

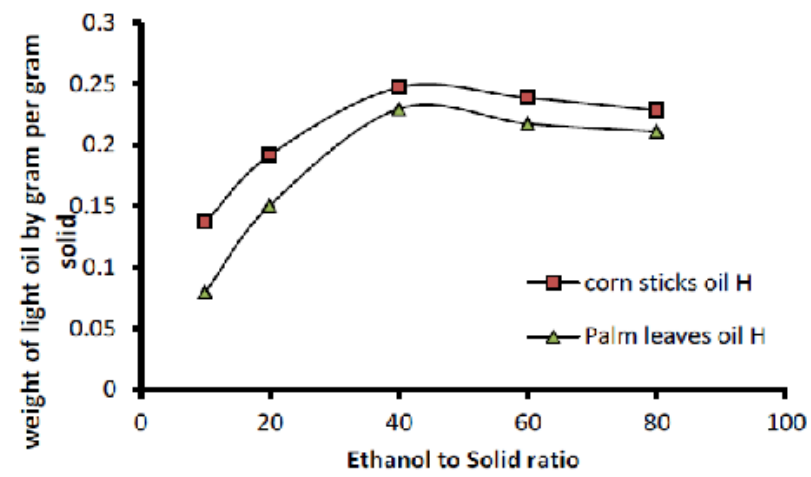

Figure 3: Relation between ethanol solid ratio and amount of heavy oil produce per gram solid.

Heavy bio-oil) for time equal 15 and $30 \mathrm{~min}$. The data obtained in Figures 1-3.

From Figures 1-3, we find that, increasing in ethanol to biomass ratio increase production of bio-oil but this effect difference from volatile, light and heavy bio oil corn sticks and palm leaves.

As increasing in ethanol to biomass ratio increase the production of volatile bio-oil the major amount obtained from corn sticks $(0.0447 \mathrm{~g} \mathrm{v}$. oil/g corn sticks) then palm leaves ( $0.00919 \mathrm{~g}$ v. oil/g palm leaves) [26].

The major function of ethanol during the liquefaction process were to provide active hydrogen, and free radicals [27] this broke the $\mathrm{C}-\mathrm{C}$ and $\mathrm{C}-\mathrm{O}$ ponds in cellulose molecules and forming Sorbitol which convert to alkanes and alkenes [24] with more hydrogenation this increase the amount of volatile material (volatile bio oil) with increasing ethanol to biomass ratio.

In opposite for liquid and heavy bio-oil production increase with increasing the ethanol to biomass ratio until reach maximum at $30 \mathrm{ml}$ ethanol/gram solids after that increase ratio decrease the production of light and heavy bio oil this due to degradation occurs for intermediate compound [23]. The maximum amount of light bio-oil (g bio-oil/g biomass) obtained at $30 \mathrm{ml}$ ethanol/gram biomass was taken from Palm leave 0.1749 then from corn stick $0.1528 \mathrm{~g} / \mathrm{g}$.

The maximum amount of heavy bio-oil ( $\mathrm{g}$ bio-oil/g biomass) was obtained from corn stick $0.247 \mathrm{~g}$ heavy oil/g corn stick then from palm leaves $0.029 \mathrm{~g} / \mathrm{g}$. 


\section{Studying the effect of retention time in bio-oil production}

Figures 4-8 shows the effect of retention time on amounts of biooil production in the liquefactions of the three agriculture waste (rice straw, corn sticks and palm leaves) at $2.5 \mathrm{~atm}$ and $220^{\circ} \mathrm{C}$. The produced amount of volatile bio oil reach to maximum at 30 min after that any increase in retention time decrease the amount of volatile oil these is due to recombination and re-polymerization of reactive fragments

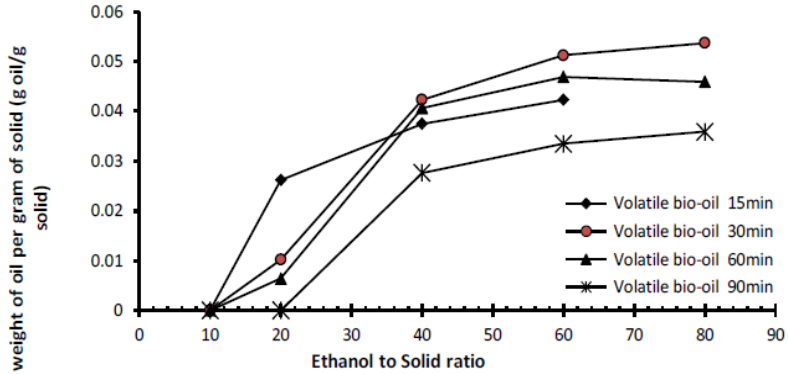

Figure 4: Amount of volatile oil (g) per gram corn sticks at different autoclaving time for rice straw.

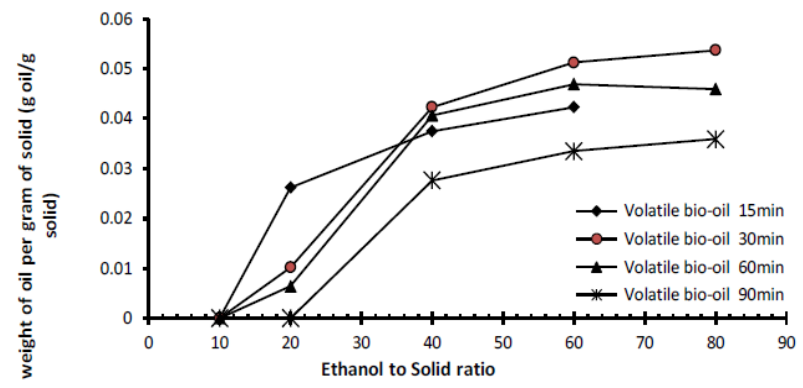

Figure 5: Amount of volatile oil (g) per gram palm leaves at different autoclaving time for rice straw.

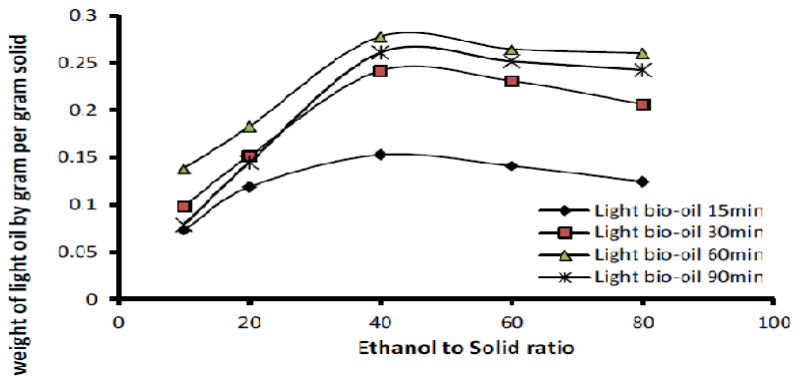

Figure 6: Relation between ethanol solid ratio and amount of light oil produce per gram palm leavs at different autoclaving time.

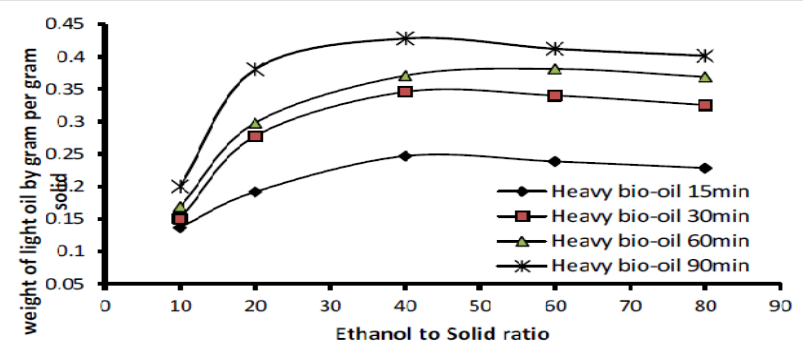

Figure 7: Relation between ethanol solid ratio and amount of heavy oil produce per gram corn sticks at different autoclaving time.

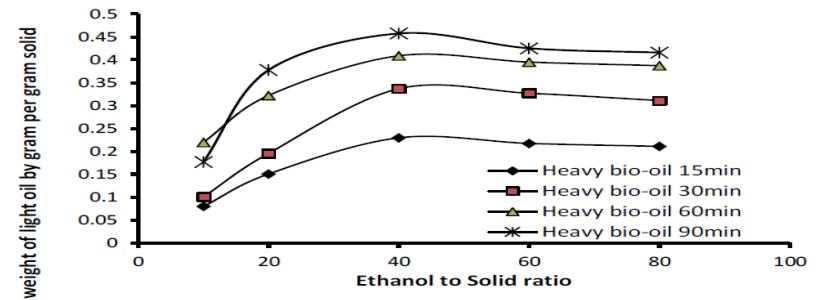

Figure 8: Relation between ethanol solid ratio and amount of heavy oil produce per gram palm leaves at different autoclaving time.

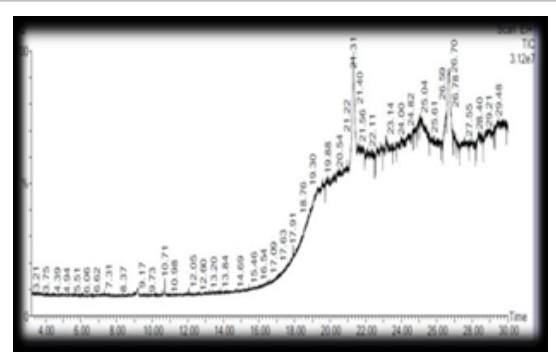

Figure 9: Chromatogram of corn sticks bio-oil by using Gas chromatograph with mass detector

\begin{tabular}{|c|c|c|c|c|}
\hline RT & $\begin{array}{c}\text { Area } \\
\%\end{array}$ & Compound Name & $\mathrm{N} \%$ & $\begin{array}{l}\text { Chemical } \\
\text { formula }\end{array}$ \\
\hline 21.311 & 8.678 & Oleic acid, 3-(octadecyloxy)propyl ester & 100 & $\mathrm{C}_{39} \mathrm{H}_{76} \mathrm{O}_{3}$ \\
\hline 19.405 & 6.212 & 1-Monolinoleoylglycerol trimethyl ether & 71.58 & $\mathrm{C}_{6} \mathrm{H}_{14} \mathrm{O}_{3}$ \\
\hline 26.688 & 5.355 & Cyclopropane, octadecamethyl- & 61.71 & $\mathrm{C} 21 \mathrm{H} 60$ \\
\hline 20.22 & 3.174 & $\begin{array}{l}\text { (t-Butyl-dimethyl -[2-methyl-2-(4-methyl- } \\
\text { pent-3-enyl)-cyclopropyl]-methanol }\end{array}$ & 36.58 & $\mathrm{C} 9 \mathrm{H} 180$ \\
\hline 19.58 & 3.114 & Stearic acid, 3-(octadecyloxy)propyl ester & 35.89 & $\mathrm{C}_{39} \mathrm{H}_{78 \mathrm{O}_{3}}$ \\
\hline 19.875 & 2.83 & $\begin{array}{c}\text { 3H-3,10a-Methano-1,2-benzodioxocin- } \\
\text { 3-ol, octahydro-7,7-dimethyl- } \\
\text {,(3à,6aá,10aá)- }\end{array}$ & 32.61 & $\mathrm{C} 26 \mathrm{H} 52 \mathrm{O}$ \\
\hline 25.042 & 2.4 & $\begin{array}{l}\text { Butanoic acid, 1a,2,5,5a,6,9,10,10a- } \\
\text { octahydro-5ahydroxy-4-(hydroxymethyl)- } \\
\text { 1,1,7,9-tetramethyl-6,11-dioxo-1H- } \\
\text { 2,8amethanocyclopenta[a]cyclopropa[e] } \\
\text { cyclodecen-5-yl ester, [1aR- } \\
\text { (1aà,2à,5á,5aá,8aà,9à,10aà }\end{array}$ & 27.66 & $\mathrm{C} 27 \mathrm{H}_{5} 4 \mathrm{O}_{3}$ \\
\hline 24.482 & 2.296 & Stearic acid, 3-(octadecyloxy)propyl ester & 26.46 & $\mathrm{C}_{39} \mathrm{H}_{78 \mathrm{O}_{3}}$ \\
\hline
\end{tabular}

Table 1: The main component of corn sticks bio-oil from gas chromatography.

[20]. By comparison the two agriculture waste (corn sticks and palm leaves) find that the maximum amount of volatile oil produce at $30 \mathrm{~min}$ and the minimum amount at $120 \mathrm{~min}$.

For light bio-oil first the amount of light oil produced increase with time until reach the maximum at $60 \mathrm{~min}$ after that the amount of light decrease with increasing time the minimum amount at $90 \mathrm{~min}$. At the start time the reactions of depolymerization of the biomass. and decomposition of the biomass monomers by cleavage, dehydration, decarboxylation and deamination occurs so the amount of light biooil increase with time until reach maximum after that increasing time make the reactive fragments recombination and repolymerization this make it large molecules and heavy oil.

Produced amount of heavy bio oil increase with increasing retention time and reach to maximum at $90 \mathrm{~min}$ this is due to recombination and re-polymerization of reactive fragments.

\section{GC-Ms Analysis}

The identification of the major components of the three types of bio-oil through GC-MS is shown in Figures 9, 10, Tables 1 and 2. 


\section{For corn sticks}

From Figure 9 and Table 1 we find that the main groups in biooil produced from corn sticks are ester and Alkanes the major number of carbon atom from $\mathrm{C}_{16}-\mathrm{C}_{39}$ the volatile amount $\left(\mathrm{C}_{6}\right)$ is too high in comparison with bio oil from rice straw either the heavy molecules is high $\left(\mathrm{C}_{39}\right)$. The bio oil from corn-sticks can be used as biodiesel fuel.

\section{For palm leaves}

From Figure 10 and Table 2 we find that the main groups in bio-oil produced from Palm Leaves are unsaturated fatty acids (Linoleic acid and tetradecenoic acid) number of carbon atom from $\mathrm{C}_{10}-\mathrm{C}_{18}$ which are have a lot of applications in pharmaceutical industry either it contain Octadecanesulphonyl chloride which use in dyes industry. The volatile amount and the heavy molecules is rarely found. The bio oil from Palm Leaves can be used in pharmaceutical and dyes industries.

\begin{tabular}{|c|c|c|c|c|}
\hline $\mathbf{R T}$ & Area\% & Compound Name & $\mathbf{N} \%$ & Chemical formula \\
\hline 23.041 & 17.264 & Linoleic acid & 100 & $\mathrm{C}_{18} \mathrm{H}_{32} \mathrm{O}_{2}$ \\
\hline 21.876 & 9.238 & $\begin{array}{c}\text { Z-8-Methyl-9-tetradecenoic } \\
\text { acid }\end{array}$ & 53.51 & $\mathrm{C}_{15} \mathrm{H}_{28} \mathrm{O}_{2}$ \\
\hline 24.597 & 5.916 & $\begin{array}{c}\text { Limonen-6-ol, pivalate } \\
\text { (13) }\end{array}$ & 34.27 & $\mathrm{C}_{10} \mathrm{H}_{16}$ \\
\hline 26.693 & 4.178 & $\begin{array}{c}11,13-\text { imethyl-12-tetradecen- } \\
\text { 1-ol acetate }\end{array}$ & 24.2 & $\mathrm{C}_{18} \mathrm{H}_{34} \mathrm{O}_{2}$ \\
\hline 23.847 & 2.911 & cis-Vaccenic acid & 16.86 & $\mathrm{C}_{18} \mathrm{H}_{34} \mathrm{O}_{2}$ \\
\hline 19.995 & 2.771 & $\begin{array}{c}\text { E-2-Octadecadecen-1-ol } \\
16.05\end{array}$ & $\mathrm{C}_{19} \mathrm{H}_{36} \mathrm{O}$ \\
\hline 27.523 & 2.689 & $\begin{array}{c}\text { Z-8-Methyl-9-tetradecenoic } \\
\text { acid }\end{array}$ & 15.58 & $\mathrm{C}_{15} \mathrm{H}_{28} \mathrm{O}_{2}$ \\
\hline 27.028 & 2.221 & $\begin{array}{c}\text { 7-Methyl-Z-tetradecen-1-ol } \\
\text { acetate }\end{array}$ & 12.87 & $\mathrm{C}_{17} \mathrm{H}_{32} \mathrm{O}_{2}$ \\
\hline 20.97 & 1.974 & Octadecane, 6-methyl- & 11.43 & $\mathrm{C}_{19} \mathrm{H}_{40}$ \\
\hline 20.63 & 1.848 & $1,2-15,16-$ Diepoxyhexadecane & 10.7 & $\mathrm{C}_{16} \mathrm{H}_{30} \mathrm{O}_{2}$ \\
\hline 24.012 & 1.716 & $\begin{array}{c}\text { 1-Octadecanesulphonyl } \\
\text { chloride }\end{array}$ & 9.94 & $\mathrm{C}_{18} \mathrm{H}_{37} \mathrm{ClO}_{2} \mathrm{~S}$ \\
\hline
\end{tabular}

Table 2: The main component of Palm leaves bio-oil from gas chromatography.

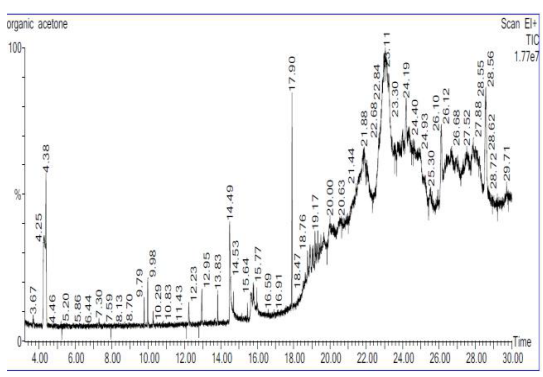

Figure 10: Chromatogram of Palm leaves bio-oil by using Gas chromatograph with mass detector.

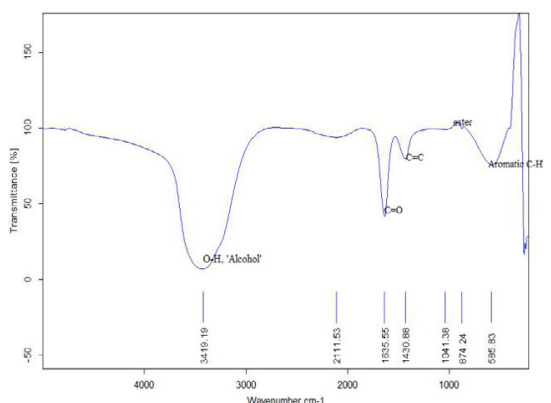

Figure 11: FT-IR spectra for bio-oil produced from corn sticks

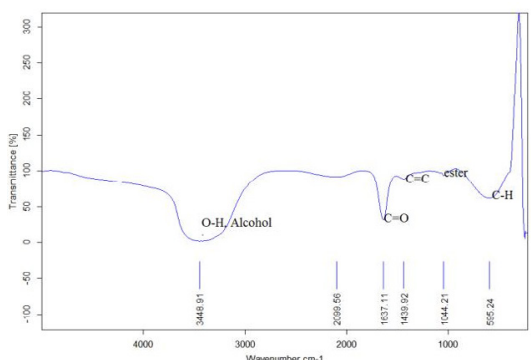

Figure 12: FT-IR spectra for bio-oil produced from palm leaves.

\begin{tabular}{|c|c|c|c|c|c|c|}
\hline $\mathbf{X}$ & $\mathbf{Y}$ & $\mathbf{X}$ (time, $\mathbf{m i n})$ & $\mathbf{Y}$ (Ratio) & $\begin{array}{c}\text { Z1 volatile } \\
\mathbf{g} / \mathbf{g}\end{array}$ & $\mathbf{Z 2 ~ l i g h t ( g / g )}$ & $\begin{array}{c}\mathbf{Z 3} \\
\text { heavy(g/g) }\end{array}$ \\
\hline-1 & -1 & 15 & 15 & 0.0122 & 0.1168 & 0.1643 \\
\hline 1 & -1 & 90 & 15 & 0 & 0.1754 & 0.2895 \\
\hline 0 & -1 & 52.5 & 15 & 0.00285 & 0.197 & 0.2279 \\
\hline-1 & 1 & 15 & 90 & 0.0449 & 0.1505 & 0.2197 \\
\hline 1 & 1 & 90 & 90 & 0.0356 & 0.23 & 0.3988 \\
\hline 0 & 1 & 52.5 & 90 & 0.04942 & 0.2953 & 0.3621 \\
\hline-1 & 0 & 15 & 15 & 0.01216 & 0.11706 & 0.16405 \\
\hline 1 & 0 & 90 & 52.5 & 0.0313 & 0.2992 & 0.4133 \\
\hline 0 & 0 & 52.5 & 52.5 & 0.04601 & 0.2955 & 0.3733 \\
\hline 0.5 & -1 & 71 & 15 & 0 & 0.16755 & 0.2412 \\
\hline 0.5 & 0 & 71 & 52.5 & 0.0392 & 0.2843 & 0.3953 \\
\hline 0.5 & 1 & 71 & 90 & 0.04022 & 0.2588 & 0.3747 \\
\hline-1 & 0.5 & 15 & 71 & 0.04362 & 0.1675 & 0.2345 \\
\hline 1 & 0.5 & 90 & 71 & 0.0348 & 0.2333 & 0.4022 \\
\hline 0 & 0.5 & 52.5 & 71 & 0.04789 & 0.2765 & 0.3709 \\
\hline
\end{tabular}

Table 3: Range and Levels of Natural and Corresponded Coded Variables for bio oil from corn sticks.

\section{FT-IR analysis for bio-oil}

The bio-oil obtained from the liquefaction process was characterized by infrared spectroscopy (FTIR). The reflectance bands were used to identify the main functional groups present. References [28-30] used to identify the FTIR groups as shown in Figures 11 and 12.

From FTIR Reflectance bands find that the bio oil produced contain carboxyl, carbonyl, Keton and ester groups.

\section{Statistical Analysis Using Matlab Software}

\section{For corn sticks}

The natural and coded variables were determined and are presented in Tables 3 and 4 [20,31-36].

\section{Linear module for volatile bio oil}

$Z_{1 \text { corn }}=-0.03192+0.0005^{\star} \mathrm{x}+0.003212^{\star} \mathrm{y}-1.829 \times 10^{-5 *} \mathrm{x}^{\star} \mathrm{y}-4.869 \times 10$ ${ }^{5 *} \mathrm{y}^{2}+1.0309 \times 10^{-7 *} \mathrm{x}^{3}-1.082 \times 10^{-7 *} \mathrm{x}^{2 *} \mathrm{y}+1.493 \times 10^{-8 *} \mathrm{x}^{\star} \mathrm{y}^{2}+2.245 \times 10$ ${ }^{7 \star} \mathrm{y}^{3}$

\section{Goodness of fit}

SSE: 0.0000274; R Square: 0.9949; Adjusted R Square: 0.9839; RMSE: 0.00232

\section{Goodness of validation}

SSE: 0.0000274; RMSE: 0.000232.

\section{Linear module for light bio oil}

$Z_{1 \text { corn }}=0.2147+0.01209 x+0.01703 y+0.0002349 x^{-2}+7.203 \times 10^{-5} x y-$ 
$0.0003373 \mathrm{y}^{2}+1.359 \times 10^{-6} \mathrm{x}^{3}-5.024 \times 10^{-7} \mathrm{x}^{2}-1.638-10^{-7} \mathrm{xy}^{2}+1.881 \times 10^{-}$ ${ }^{6} \mathrm{y}^{3}$

\section{Goodness of fit}

SSE: 0.0007673; R-Square: 0.9874; Adjusted R-square: 0.9646; RMSE: 0.01239 .

\section{Goodness of validation}

SSE: 0.0007673; RMSE: 0.01239.

\section{Linear module for heavy bio oil}

$\mathrm{Z}_{\mathrm{h}, \quad \text { corn }}=-0.01811+0.006373 \mathrm{X}+0.01607 \quad \mathrm{Y}-0.00001177^{\star} \mathrm{X}^{2}+6.413$ $\times 10^{-5} * \mathrm{X} * \mathrm{Y}-0.000736 \mathrm{Y}^{2}+730 \times 10^{-7} \mathrm{X}^{3}-1.73 \times 10^{-7} \mathrm{X}^{2} \mathrm{Y}-7.804 \times 10$

${ }^{7} \mathrm{XY}^{2}+1.174 \times 10^{-6} \mathrm{Y}^{3}$

\section{Goodness of fit}

SSE: 0.0001781; R-Square Adjusted: 0.9985; R-Square: 0.9957; RMSE: 0.005969 .

\section{Goodness of validation}

SSE: 0.0001781 , RMSE: 0.005969.

\section{For Palm leaves}

The natural and coded variables were determined and are presented in Table 4

\section{Linear module for volatile bio oil}

$\mathrm{Z}_{1 \text { palm }}=0.02534+0.001302 \mathrm{x}+0.001209 \mathrm{y}-2.605 \times 10-5 \mathrm{x}^{2}-2.1 .7 \times$ $10^{-7 *} \mathrm{x}^{\star} \mathrm{y}-1.542 \times 10^{-5} \mathrm{y}^{2}+1.639 \times 10^{-7} \mathrm{x}^{3}-8.407 \times 10^{-8} \mathrm{x}^{2} \mathrm{Y}-1.109 \times 10^{-7}$ $\mathrm{xy}^{2}+2.766 \times 10^{-8} \mathrm{y}^{3}$

\section{Goodness of fit}

SSE: 0.00001248; R-Square: 0.986; Adjusted R-Square: 0.9609; RMSE: 0.00232 .

\section{Goodness of validation}

SSE: 0.00001248; RMSE: 0.00158.

\section{Linear module for Light bio oil}

$Z_{1, \text { palm }}=-0.04436+0.00437 \mathrm{X}+0.007127 \mathrm{Y}-6.927 \times 10^{-5} \mathrm{X}^{2+} 7.759 \times$

\begin{tabular}{|c|c|c|c|c|c|c|}
\hline $\mathbf{X 1}$ & $\mathbf{y}$ & $\begin{array}{c}\mathbf{x} \text { (time, } \\
\mathbf{m i n} \text { ) }\end{array}$ & $\mathbf{y}$ (Ratio) & Volatile & Light & Heavy \\
\hline-1 & -1 & 15 & 15 & 0.00413 & 0.1006 & 0.11215 \\
\hline 1 & -1 & 90 & 15 & 0 & 0.1215 & 0.2765 \\
\hline 0 & -1 & 52.5 & 15 & 0.00465 & 0.1571 & 0.2398 \\
\hline-1 & 1 & 15 & 90 & 0.00488 & 0.11655 & 0.2077 \\
\hline 1 & 1 & 90 & 90 & 0.01577 & 0.2379 & 0.4112 \\
\hline 0 & 1 & 52.5 & 90 & 0.02215 & 0.2418 & 0.3632 \\
\hline-1 & 0 & 15 & 52.5 & 0.01673 & 0.1478 & 0.2247 \\
\hline 1 & 0 & 90 & 52.5 & 0.007 & 0.2607 & 0.4825 \\
\hline 0 & 0 & 52.5 & 52.5 & 0.02295 & 0.2629 & 0.3833 \\
\hline 0.5 & -1 & 71 & 15 & 0.00117 & 0.1466 & 0.2731 \\
\hline 0.5 & 0 & 71 & 52.5 & 0.01555 & 0.2657 & 0.4096 \\
\hline 0.5 & 1 & 71 & 90 & 0.0178 & 0.2582 & 0.4103 \\
\hline-1 & 0.5 & 15 & 71 & 0.01315 & 0.1332 & 0.2139 \\
\hline 1 & 0.5 & 90 & 71 & 0.01214 & 0.2495 & 0.4225 \\
\hline 0 & 0.5 & 52.5 & 71 & 0.02356 & 0.2528 & 0.3729 \\
\hline
\end{tabular}

Table 4: Range and levels of natural and corresponded coded variables for bio oil from palm leaves.
$10^{-5} * \mathrm{X} * \mathrm{Y}-0.0001375 \mathrm{Y}^{2}+2.558 \times 10^{-7} \mathrm{X}^{3}-2.337 \times 10^{-7} \mathrm{X}^{2} \mathrm{Y}-3.384 \times 10$ ${ }^{7} \mathrm{XY}+7.198 \times 10^{-7} \mathrm{Y}^{3}$

\section{Goodness of fit}

SSE: 0.0001195; R-Square: 0.998; Adjusted R-Square: 0.994.

\section{Goodness of validation}

SSE: 0.0001195; RMSE: 0.004889 .

\section{Linear module for heavy bio oil}

$\mathrm{Z}_{\mathrm{hplm}}=-0.1544+0.0059 \mathrm{X}+0.01607 \mathrm{Y}-6.472 \times 10^{-5} \mathrm{X}^{2}+6.726 \times 10$ ${ }^{5} * \mathrm{X} * \mathrm{Y}-0.0002925 \mathrm{Y}^{2}+2.572 \times 10^{-7} \mathrm{X}^{3}-1.447 \times 10^{-7} \mathrm{X}^{2} \mathrm{Y}-4.444 \times 10$ ${ }^{7} \mathrm{XY}^{2}+1.622 \times 10^{-6} \mathrm{Y}^{3}$

\section{Goodness of fit}

SSE: 0.001537; R-Square: 0.9902; Adjusted R-Square: 0.9726.

\section{Goodness of validation}

SSE: 0.001537; RMSE: 0.00158.

\section{Results and Discussion}

Examination of the table shows that the models is highly correlation coefficient $(\mathrm{R} 2)>0.9$, the model fits the experimental data fitted with a third-order polynomial model (eqns. (1)-(6)), the model being rejected if the R2 value is less than 0.8 [32]. The 3D surface plotted in Figures 13-23 show that the combination reaction time, min and 100 ethanol/ solid ratio significant effects volatile bio-oil (g/g). Figures demonstrate that the increase in reaction time, min with the increase in liquid/Solid ratio concentration enhance the efficiency of volatile bio-oil weight production until reach the maximum then the production rate decrease as a result of re-polymerization but we find that the rate of production of volatile bio-oil is very small, comparison with the rate of production of light and heavy bio-oil [33-39].

In the similar way, the $3 \mathrm{D}$ surface plotted to light bio-oil production

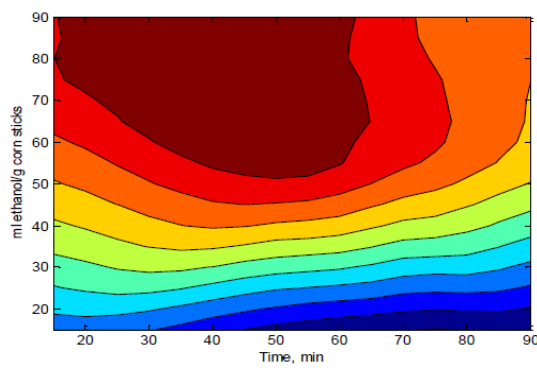

Figure 13: Contour plot for volatile bio-oil produced from corn sticks versus difference in time and ethanol/solid ratio.

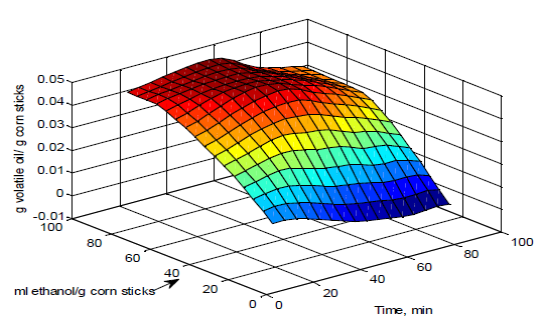

Figure 14: Surface plot for volatile bio-oil produced from corn sticks versus difference in time and ethanol/solid ratio. 


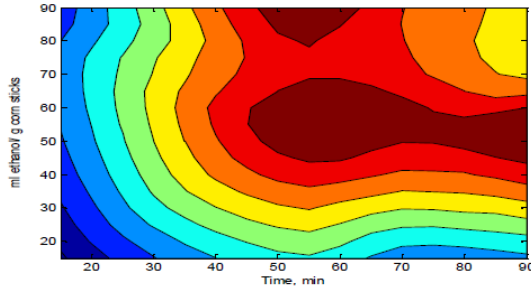

Figure 15: Contour plot for light bio oil produced from corn sticks versus different time and ethanol/solid ratio.

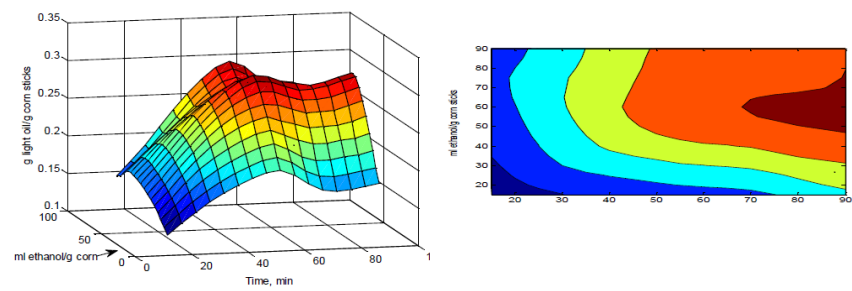

Figure 16: (A) surface plot for light oil produced from corn sticks versus differen time and ethanol/solid ratio (B) contour plot for heavy oil produced from corn sticks versus different in time and ethanol/solid ratio.

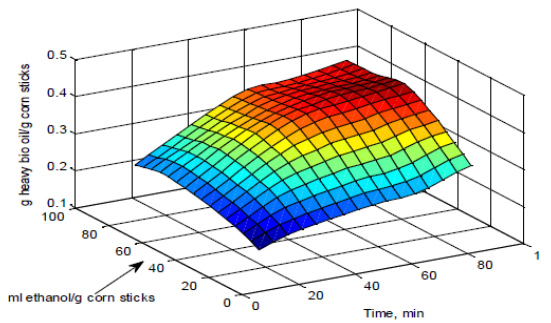

Figure 17: Surface plot for heavy bio-oil produced from corn sticks versus different in time and ethanol/solid ratio.

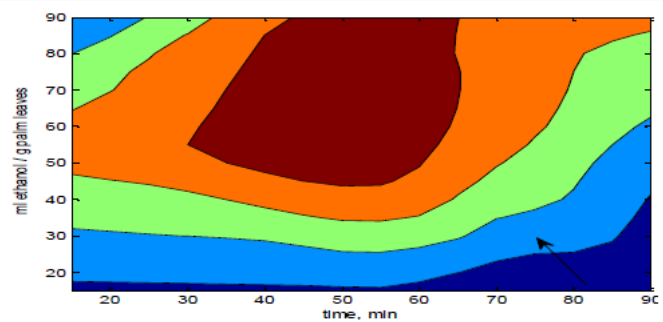

Figure 18: Contour plot for volatile oil produced from palm leaves versus time and ethanol/solid ratio.

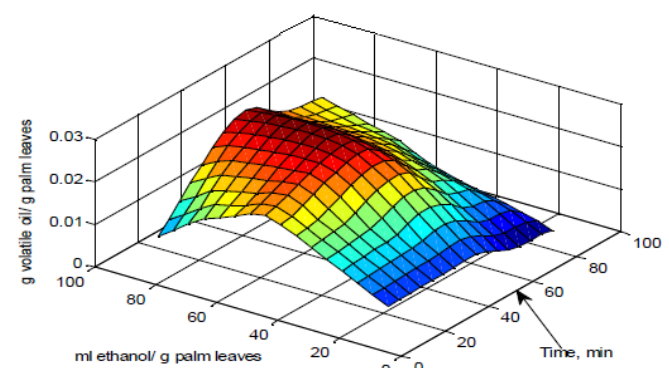

Figure 19: Surface plot for volatile oil produced from palm leaves versus time and ethanol/solid ratio.

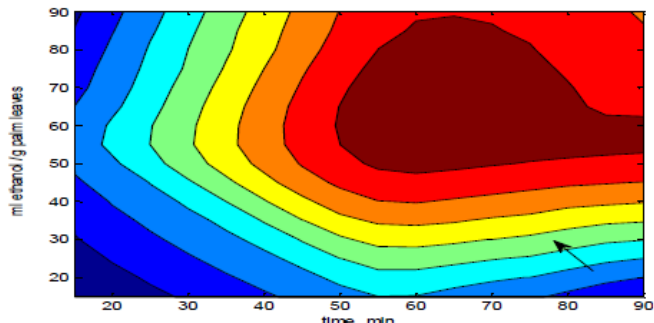

Figure 20: Contour plot for light oil produced from palm leaves versus time and ethanol/solid ratio.

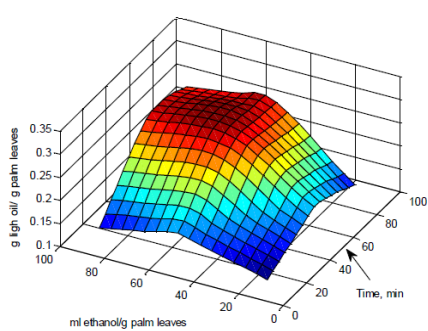

Figure 21: Surface plot for light oil produced from palm leaves versus time and ethanol/solid ratio linear module for heavy bio oil.

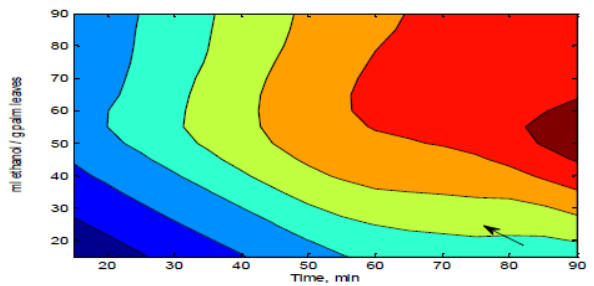

Figure 22: Contour plot for light oil produced from palm leaves versus time and ethanol/solid ratio.

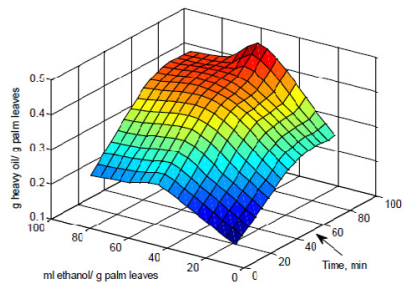

Figure 23: Surface plot for heavy oil produced from palm leaves versus time and ethanol/solid ratio.

shows that the combination Reaction Time, min and liquid/solid ratio has a significant effects on Light bio-oil production these figures demonstrates that the increase in Reaction Time, min with the increase in liquid/solid ratio enhance the efficiency of light bio-oil production until reach the maximum then the production rate decrease.

For heavy bio-oil production the figures demonstrate that the increase in Reaction Time, min with the increase in liquid/solid ratio enhance the efficiency of heavy oil production rate until reach the maximum. Either any increase in reaction time, increase the rate of polymeraization and combination which increase the rate of heavy-oil production.

Response surface analysis was used to determine optimum conditions of the operating variables in the production of bio-oil (Table 5) [20]. 


\begin{tabular}{|c|c|c|c|c|}
\hline $\begin{array}{c}\text { Raw } \\
\text { material }\end{array}$ & Bio-oil type & Time, Min & $\begin{array}{c}\text { Ethanol/Solid } \\
(\mathbf{I} / \mathbf{g})\end{array}$ & $\begin{array}{c}\text { Bio-oil Produced } \\
\text { g oil/g solid }\end{array}$ \\
\hline \multirow{3}{*}{ Rice straw } & Volatile & 38 & 42 & 0.02975 \\
\cline { 2 - 5 } & Liquid & 52.5 & 35 & 0.2450 \\
\cline { 2 - 5 } & heavy & 52.5 & 35 & 0.237 \\
\hline \multirow{3}{*}{ Corn sticks } & Volatile & 38 & 42 & 0.0464 \\
\cline { 2 - 5 } & Liquid & 52.5 & 35 & 0.2106 \\
\cline { 2 - 5 } & heavy & 52.5 & 35 & 0.2470 \\
\hline \multirow{3}{*}{ Palm leaves } & Volatile & 38 & 42 & 0.0131 \\
\cline { 2 - 5 } & Liquid & 52.5 & 35 & 0.2549 \\
\cline { 2 - 5 } & heavy & 52.5 & 35 & 0.0318 \\
\hline
\end{tabular}

Table 5: Optimum conditions for all types produced of bio oil by using matlab7

\section{Conclusions}

-The result of that investigation reveals the production of bio-oils from agriculture waste.

-The optimum conditions of producing light and heavy bio-oil are ethanol to solid ratio $30 \mathrm{ml} / \mathrm{g}$ and at $60 \mathrm{~min}$ retention time but for volatile bio-oil the best conditions are $40 \mathrm{ml}$ ethanol/g solids and 30 min.

- The characteristics of bio-oil which produced from corn sticks contain high present of heavy constituents $\mathrm{C} 20-\mathrm{C} 38$ and high percent of volatile bio-oil T C6-C9 than Bio-oil produced from Palm leaves.

-The characteristics of bio-oil which produced from palm leave mainly unsaturated acids C10-C18.

-The optimum amount of volatile, light and heavy bio oil produced from corn sticks at optimum conditions are $0.0447 \mathrm{~g}$ volatile oil/g corn sticks, $0.1749 \mathrm{~g}$ light oil/g corn sticks and $0.247 \mathrm{~g}$ heavy oil/g corn stick

-From GC-MS and FT-IR analysis the bio-oil produced from corn stick are ester and Alkanes groups which use either as biofuel and bio oil from palm leaves are unsaturated fatty acids (Linoleic acid and tetradecenoic acid) which are have a lot of applications in pharmaceutical industry either it contain Octadecanesulphonyl chloride which use in dyes industry.

- Statistical analysis by matlab7 software's is studied for the factors and response and the related equation are obtained.

- The optimum conditions are obtained from matlab 7 for light and heavy bio oil produced are $52.5 \mathrm{~min}$ for retention time and $35 \mathrm{ml} / \mathrm{g}$ ethanol/solid ratio, but for volatile bio oil the optimum conditions are $38 \mathrm{~min}$ for retention time and $42 \mathrm{ml} / \mathrm{g}$ ethanol/solid ratio, which is near to the experimental work.

- To obtain the relation between the two factors for every response find by Surface plot.

\section{References}

1. Liu HM, Xie XA, Li MF, Sun RC (2012) Hydrothermal Liquefaction of Cypress: Effects of Reaction Conditions on 5-Lump Distribution and Composition. Journal of Analytical and Applied Pyrolysis 177-183.

2. Yaning Z, Ghaly AE, Bingxi Li (2012) Availability and Physical Properties of Residues from Major Agricultural Crops for Energy Conversion Through Thermochemical Processes. American Journal of Agricultural and Biological Science 7: 312-321.

3. Elfeki M, Tkadlec T (2015) Treatment of Municipal Organic Solid Waste in Egypt. J Mater Environ Sci 6: 756-764

4. Blin J, Volle G, Girard P, Bridgwater T, Meier D, et al. (2007) Biodegradability of Biomass Pyrolysis Oils Comparison to Conventional Petroleum Fuels and Alternatives Fuels in Current Use. Fuel 86: 2679-2686.
5. FAO (2002) Food and Agriculture Organization of the United Nations. Date of Palm Cultivations.

6. Hussein SDA, Sawan OM (2010) The Utilization Of Agricultural Waste as One of The Environmental Issues in Egypt (A Case Study). Journal of Applied Sciences Research 6: 1116-1124

7. Yuanhui Z (2010) Hydrothermal Liquefaction to Convert Biomass into Crude Oil. Biofuels from Agricultural Wastes and By Products 80252-80257.

8. Baker EG, Elliott DC (1988) Catalytic Hydrotreating of Biomass-derived Oils, In Pyrolysis Oils from Biomass. American Chemical Society 228-240.

9. Yanik J, Kornmayer C, Saglam M, Yuksel M (2007) Fast Pyrolysis of Agriculture Waste; Characterization Of Pyrolysis Products. Fuel Process Technol 88: 942 947.

10. Bridgwater AV, Peacocke GVC (2000) Fast pyrolysis processes for biomass. Renewable and Sustainable Energy Reviews 1: 1-73.

11. Li XZ, Yuan GM, Zeng JY, Tong Y, Yan HT, et al. (2009) Liquefaction of Rice Straw in Sub- and Supercritical 1,4-Dioxane-Water Mixture. Fuel Processing Technology 90: 657-663.

12. Xu Y, Hu X, Li W, Shi Y (2011) Preparation and Characterization of Bio-Oil from Biomass Progress in Biomass and Bioenergy Production.

13. Philippidis GP, Smith TK, Wyman CE (1993) Study of the Enzymatic Hydrolysis of Cellulose for Production of Fuel Ethanol by the Simultaneous Saccharification and Fermentation Process. Biotechnology and Bioengineering 41: 846-853.

14. Yan-Fen L, Shu-Rong W, Ma Xiao-Qian M (2004) Study of Reaction Mechanisms in Cellulose Pyrolysis 1: 407

15. Douglas C, Elliott A, Biller P, Ross AB, Schmidt AJ, et al. (2015) Hydrotherma Liquefaction of Biomass: Developments from Batch to Continuous Process. Bioresource Technology 178: 147-156.

16. Kruse A, Gawlik A (2003) Biomass Conversation in Water At $330-410^{\circ} \mathrm{C}$ and 30-50 Mpa, Identification of Key Compound for Indicating Different Chemical Reaction Pathway. Ind Eng Chem Res 2: 267-279.

17. Shen D, Xiao R, Gu S, Zhang H (2013) The Overview of Thermal Decomposition of Cellulose in Lignocellulosic Biomass.

18. Demirbas A (2007) Biodiesel: A Realistic Fuel Alternative for Diesel Engines. Springer-Verlag London Limited.

19. Zheng (2013) Liquefaction of Biomass. Bio Resources 1: 648-662.

20. Adjaye JD, Sharma R, Bakhshi NN (1992) Characterization and Stability Analysis of Wood-Derived Bio-Oil. Fuel Processing Technology 3: 241-256.

21. Blin J, Volle G, Girard P, Bridgwater T, Meier D (2007) Biodegradability of Biomass Pyrolysis Oils: Comparison to Conventional Petroleum Fuels and Alternatives. Fuels in Current Use. Fuel 17: 2679-2686.

22. Hu X, XuY, Wang Q, Jiang S, Zhu X (2008) Tribological Performance of Distilled Biomass Oil from Rice Straw by Pyrolysis Process. Journal of Synthetic Lubrication 3: 95-104.

23. Duan P, Savage PE (2010) Hydrothermal Liquefaction of a Microalga with Heterogeneous Catalysts. Industrial \& Engineering Chemistry Research 1 : $52-61$.

24. Galletti AMR, Antonett C (2011) Biomass Pre-Treatment: Separation of Cellulose, Hemicellulose and Lignin. Existing technologies and perspective. Castro Marina.

25. Wang L, Shen SQ, Yang SH, Shei XG (2010) Experimental Investigation of Pyrolysis Process of Corn Straw. Int J Law Carbon Tech 4: 182-185.

26. Wang LF, Cheng YC (2011) Determination the Content of Cellulose by Nititic Acid/Ethanol Method. Chemical Research 4: 52-55.

27. Mohamed OA, Ashour I (2016) Production of Bio-oil from Rice Straw. International Journal of Chemical and Environmental Engineering 2.

28. Li J, Kazakov A, Dryer FL (2004) Experimental and Numerical Studies of Ethanol Decomposition Reactions, Ethanol Decomposition. J Phys Chem A 108(38): 7671-7680.

29. Liang G, He L, Cheng $\mathrm{H}$, Li W, Li X et al. (2014) The Hydrogenation/ Dehydrogenation Activity of Supported Ni Catalysts and their Effect on Hexitols Selectivity in Hydrolytic Hydrogenation of Cellulose. Journal of Catalysis 309 468-476. 
30. Liang G, Cheng H, Li W, He L, Yu Y, et al. Green Chem 14: 2146.

31. Huang HJ, Yuan XZ, Zeng GM, Wang JY, Li H, et al. (2011) Thermochemical Liquefaction Characteristics of Microalgae in Sub-and Supercritical Ethanol, Fuel Processing Technology 92: 147-153.

32. Chen $Y$, Wu Y, Zhang, PL, Hua DR, Yang MD, et al. (2012) Direct Liquefaction of Dunaliella Tertiolecta for Bio-Oil in Sub/Supercritical Ethanol-Water, Bioresource Technology 124: 190-198.

33. Xu CB, Etcheverry T (2008) Hydro-Liquefaction of Woody Biomass in Sub- and Super-Critical Ethanol with Iron-Based Catalysts. Fuel 87: 335-345.

34. Neil Glagovich (2005) Infrared Spectroscopy Page.

35. Peter R (2007) Fourier Transform Infrared Spectroscopy.
36. Peterson AA, Vogel F, Lachance RP, Fröling M, Antal MJ, et al. (2008) Thermochemical Biofuel Production in Hydrothermal Media: A Review of Sub- and Supercritical Water Technologies. Energy \& Environmental Science 1: 32-65.

37. Montgomery DC (1991) Design and Analysis of Experiments.

38. Simpson TW, Peplinski JD, Koch PN, Allen JK (1997) On The Use Of Statistics in Design and the Implications for Deterministic Computer Experiments. ASME Design Engineering Technical Conferences, September 14-17, 1997 Sacramento, California.

39. Tony MA, Zhao YQ, Fu JF, Tayeb AM (2008) Conditioning of Aluminium-Based Water Treatment Sludge with Fenton's Reagent: Effectiveness and Optimising Study to Improve Dewaterability. Chemosphere 72: 673-677. 